VELICU, D., «Los contratos bancarios en el nuevo Código Civil rumano. Un análisis crítico de la reciente reforma»,

REDUR II, diciembre 20I3, págs. I39-I47. ISSN I695-078X

\title{
LOS CONTRATOS BANCARIOS EN EL NUEVO CÓDIGO CIVIL RUMANO. UN ANÁLISIS CRÍTICO DE LA RECIENTE REFORMA.
}

\author{
Dan VELICU
}

\author{
ABOGADO \\ PROFESOR DE LA UniVERSidAd Nicolae Titulescu De BuCAREST (RumANíA)
}

SUMARIO: I. Consideraciones preliminares. II. Cuenta corriente en el nuevo Código Civil rumano. III. El depósito bancario. IV. La apertura de crédito. V. El contrato de cajas de seguridad; VI. Conclusiones.

RESUMEN: El nuevo Código Civil rumano que entró en vigor el i de octubre de 20II fue el resultado de una amplia reforma que logró la unificación del derecho privado. El nuevo Código absorbió la mayor parte de las normas del Código de Comercio en cuanto al comercio terrestre y varias instituciones del derecho privado contenidas en los reglamentos y directivas europeas. Más allá de estos dos grandes objetivos, por primera vez, se regularon los contratos bancarios. Este estudio tiene como propósito destacar los modelos inspiradores del nuevo Código Civil y analizar la funcionalidad de los conceptos utilizados.

PALABRAS ClAVE: Código Civil, contratos bancarios, cuentas corrientes, depósitos bancarios, cajas de seguridad.

ABSTRACT: The new Romanian Civil Code, entered into force on October ist 2oil, was the aim of an extensive legal reform which achieved the unification of the private law. The new Code absorbed the largest part of the land commerce regulations from the former commerce code and several institutions of the private law contained in the European regulations and directives. Beyond these two major objectives, for the first time there were regulated the bank contracts. This study aims to highlight the inspiring models of the new Civil Code and to analyse the functionality of the newly used concepts.

KEYWORDS: Civil Code, bank contracts, bank current account, bank deposit, rental of value boxes.

\section{Consideraciones preliminares}

Después de un proceso que duró más de ocho decenios, el nuevo Código Civil rumano (NCCR), publicado en el Boletín Oficial el 24 de julio 2009, entró en vigor el I de octubre 20II, sustituyendo al Código Civil de I864, versión mejorada del Código de Napoleón y de los libros I, III y IV del Código de comercio de I887, copia del Código 
italiano de I882. El libro II, que regula el comercio marítimo, será sustituido por la promulgación del futuro Código de la navegación.

Los autores de la reforma se propusieron tanto la modernización de las instituciones civiles y comerciales, a través de la unificación del derecho civil y mercantil, como la armonización del derecho nacional respecto al derecho europeo, tanto en la esfera de los contratos como en la esfera de la responsabilidad extracontractual.

La reforma del derecho privado rumano perseguía la modernización de las instituciones anteriores, pero esta modernización debía mantenerse en el marco del sistema romanístico acogido por tradición. En este sentido, fueron utilizados como fuentes de inspiración el nuevo Código Civil de Quebec -especialmente en cuanto al derecho de las obligaciones y de los contratos «civiles»- y el Código Civil italiano de I942.

Este proceso de «modernización» fue también una buena ocasión para regular ciertas categorías de contratos, entre los cuales los contratos bancarios parecen ser los más relevantes.

El Código de Comercio, aunque consideraba expresamente como mercantiles -actos de comercio- las operaciones bancarias, no contenía normas especiales sobre los contratos bancarios ${ }^{I}$. El Código de Comercio español de 1885 o los Códigos alemanes tampoco contenían reglas especiales. Parecía entenderse que la banca desempeñaba una función esencialmente mediadora, como los otros «actos de comercio», pero mediadora del crédito.

En la doctrina prevalente del siglo XIX, recibida por los tribunales de justicia, los contratos bancarios fueron considerados aplicaciones de un esquema que se puede encajar en los moldes clásicos del derecho mercantil y civil (depósito, préstamo, comisión, prenda etc. $)^{2}$.

La falta de necesidad de normas especiales fue sostenida incluso en los trabajos preparatorios que precedieron el nuevo Código Civil italiano ${ }^{3}$.

Finalmente, este Código reconoció en el capítulo XVII del libro IV, y por primera vez, el perfil autónomo de los contratos bancarios.

Hoy en día es universalmente admitido que el concepto de contrato bancario está condicionado por el marco regulatorio publico de la actividad de intermediación en el mercado financiero ${ }^{4}$.

El derecho de la Unión Europea introduce a través el art. 4.I. de la Directiva 2006/48/CE del Parlamento y del Consejo, de I4 de julio de 2006, el concepto más amplio de «entidad de crédito» sustituyendo la noción de «banco» utilizada comúnmente.

\footnotetext{
${ }^{\mathrm{I}}$ Véase el art. 3 del Codigo de comercio italiano del I882.

${ }^{2}$ GARRIGUES, J., Contratos bancarios, Madrid, editorial Aguirre, I958, pág. I5. Por ejemplo, en la doctrina alemana puede verse esta cuestion en HERRMANN, H., «Banks Customer Relationship in German Law and Practice», en HORN, N. (ed.), German Banking Law and Practice in International Perspective, Berlin, de Gruyter, I999, págs. 87 y ss.

${ }^{3}$ MOSSA, R., «Saggio critico sul progetto del nuovo Codice di comercio», en Annuario di diritto commerciali e di studi legislativi, I, I927, pág. 230.

${ }^{4}$ TAPIA HERMIDA, A. J., «El concepto y la clasificación de los contratos bancarios», en SEQUEIRA, A., GADEA, E. y SACRISTÁN, F. (dirs), La contratación bancaria, Madrid, Dykinson, 2007, pág. I32.
} 


\section{Cuenta corriente en el nuevo Código Civil rumano}

Como todos los contratos mercantiles, a través de la reforma, el contrato de cuenta corriente está regulado en el título IX del libro V del Código Civil (arts. 2I7I a 2I83) que trata de los contratos especiales.

Contrariamente al Código de Comercio español de 1885 las disposiciones contenidas en los arts. 370 y siguientes del Código de Comercio rumano enumeraban los efectos jurídicos y los modos de extinción pero no fijaban las condiciones necesarias para que se pudiera concluir el contrato perfecto y tampoco definían el contrato de cuenta corriente mercantil ${ }^{5}$.

El nuevo Código Civil define en su artículo 2I7I este contrato como aquel en cuya virtud las partes -llamados cuentacorrentistas- se comprometen a registrar en una cuenta los créditos derivados de las remesas recíprocas, considerándolos como no exigibles e indisponibles hasta el cierre de la cuenta.

El saldo que resulte a la clausura de la cuenta constituye un crédito exigible. Si el pago no es solicitado, el saldo será considerado como primera remesa de una cuenta nueva y el contrato se entenderá renovado por tiempo indefinido.

El reconocimiento de la autonomía del contrato de cuenta corriente bancaria fue objeto de amplios debates en la doctrina ${ }^{6}$. A diferencia del Código Civil italiano, que no reconoce de manera expresa esta institución ${ }^{7}$, la disciplina de la cuenta corriente bancaria está principalmente regulada por el arts. 2184 y siguientes del Código Civil rumano contenidos en el capítulo $\mathrm{XV}$, denominado «Cuenta corriente bancaria y otros contratos bancarios».

Parece que los autores de la reforma quisieron reconocer una fisionomía especial a esta institución, incluyendo en el capítulo que trata los contratos bancarios diversas disposiciones que regulan la cuenta corriente bancaria, pero el carácter autónomo no resulta obvio. Además, el capítulo analizado no contiene definición alguna del concepto ${ }^{8}$. Y en ausencia de una definición legal es discutible si se puede aceptar el carácter autónomo de dicha institución.

Algunas normas especiales añadidas por el capítulo XV fortalecen la opinión que la cuenta corriente bancaria está regulada, en realidad, como una subespecie del contrato de cuenta corriente?

De una manera similar al Código Civil italiano, las disposiciones de nuestro Código Civil fijan derechos y obligaciones en varias hipótesis en las que entre las partes hay contratos $u$ operaciones bancarias.

En este sentido, según el art. 2I84 NCCR -que imita el art. I852 del Código Civil italiano-, cuando los depósitos bancarios, el crédito u otra operación bancaria, se realizan a

\footnotetext{
${ }^{5}$ Cfr. art.346 a 348 del Código de Comercio italiano.

${ }^{6}$ GARRIGUES, J., Contratos bancarios, cit., págs. II8 y ss.

${ }^{7}$ Cfr. arts. I852 a I857 Código Civil italiano.

${ }^{8}$ Véase la definición de GARRIGUES, J., Contratos bancarios, cit., págs. II5 y ss.

${ }^{9}$ Véase el art.I857 del Código Civil italiano.
} 
través de la cuenta corriente, el titular de la cuenta puede disponer en cualquier momento del saldo acreedor de la cuenta, respetando el plazo de preaviso establecido anteriormente por las partes.

A su vez, el art. 2I85 del Código Civil impone la compensación de todas las cuentas -no importa la moneda-, salvo estipulación contraria de las partes.

Si el contrato de cuenta corriente bancaria es celebrado a término indefinido, en virtud del art. 2I88 del Código Civil, cualquiera de las partes podrá dar por terminado el contrato, respetando un plazo de preaviso de I5 días en ausencia de otro término previsto por el contrato o por los usos, bajo la pena de pagar los daños y perjuicios.

Sensiblemente diverso al art. I855 del Código Civil italiano -muy probablemente la fuente de inspiración, que tomaba en consideración solamente las operaciones realizadas a través de la cuenta corriente-, el art. 2I 88 se refiere de una manera general a la terminación del contrato de cuenta corriente bancaria.

Por otra parte, imponer un plazo de preaviso de I5 días sería superfluo, en mi opinión, dado que el art. 2I83 par. 2 NCCR, que tiene aplicación general respecto al contrato de cuenta corriente, fija el mismo término en los contratos por tiempo indefinido.

El art. 2I87 par. I NCCR reemplaza un uso bancario en el caso de fallecimiento del titular: se reconoce a los herederos la copropiedad hasta el momento de la división de la herencia. Como consecuencia, para realizar operaciones bancarias a través de la cuenta el texto legal exige el consentimiento de todos los copropietarios.

El acreedor personal de uno de los herederos no puede solicitar el embargo del saldo, pero puede pedir la división judicial de la herencia (art. 2187 par. 2 NCCR). Y cuando hay una o más deudas del titular de la cuenta, la responsabilidad de los coherederos es divisible (art. 2I87 par. 3 NCCR).

Dichas normas resuelven algunas dificultades encontradas en la práctica bancaria ${ }^{\text {Io }}$, pero no contribuyen a la consolidación de la autonomía del contrato.

\section{El depósito bancario}

Con respecto al Código Civil italiano, el rumano tiene menos normas que regulan el depósito. Los autores de la reforma renunciaron a la regulación de la libreta de ahorro objeto de los art. I835 y I836 del código italiano-, dado que hoy en día no se utiliza en la práctica bancaria.

La nueva normativa establece una distinción fundamental entre las dos formas principales: el depósito de dinero y el depósito de títulos valores.

El depósito de dinero es aquel contrato por el cual el instituto de crédito «adquiere la propiedad del dinero depositado y se compromete a devolver la misma cantidad de dinero, la misma especie, en el plazo convenido o en cualquier momento, a petición del depositante» (art. 2I9I par. I NCCR). En la última hipótesis, los partes tienen la obligación

\footnotetext{
${ }^{10}$ ALONSO-MUÑUMER, Ma . E., «El contrato de cuenta corriente bancaria», en SEQUEIRA, A., GADEA, E. y SACRISTÁN, F. (dirs), La contratación bancaria, cit., págs. 458-459.
} 
de respetar el plazo de preaviso convenido en el contrato o, en su defecto, el plazo de preaviso establecido por los usos y costumbres (art. 2I9I par. 2 NCCR).

A diferencia de la regulación italiana (art. I834), los autores del Código rumano utilizaron dos términos idéntico, fondos y dinero, sin haber razón alguna para establecer esta distinción.

En ausencia de estipulación contraria, los depósitos sucesivos y los retiros se realizarán, en principio, en la sucursal del instituto de crédito donde se inicióla relación contractual.

El texto establece el lugar donde ha de ejecutarse la obligación principal del instituto de crédito, respecto al artículoi834 del Código italiano que establece que las operaciones sucesivas se realizaran en la «sede del banco».

Además, el texto rumano prevé que la banca está obligada a proporcionar la información sobre las transacciones de los clientes en sus cuentas en forma gratuita y periódica (art. 2I9I par. 3 NCCR). En ausencia de solicitud, la información será enviada mensualmente, en las condiciones y en la forma convenida por las partes.

En cuanto a la segunda tipología de la institución, por depósito de títulos valores, según el art. 2I92 NCCR, el instituto de crédito está autorizado para la administración de los títulos recibidos.

A diferencia del Código civil italiano, que retiene las obligaciones esenciales del instituto de crédito (custodiar los títulos, exigir los intereses o los dividendos, comprobar los sorteos para la atribución de premios o para el reembolso del capital, cuidar de los cobros por cuenta del depositante y, en general, proveer a la tutela de los derechos inherentes a los títulos) ${ }^{\mathrm{II}}$, el art. 2I92 par. I NCCR reenvía a una nueva institución regulada por el Código civil, la Administración de los bienes del otro (título V, arts. 792 a 857 NCCR). Y aquí hay que destacar las normas que regulan la obligación de invertir el dinero (art. 798 NCCR), las atribuciones del gerente (art. $800 \mathrm{NCCR}$ ), la obligación de diligencia, honestidad y realidad (art. 803 NCCR), el conflicto de intereses (art. 804 NCCR) y las inversiones consideradas seguras (arts. 83I a 836 NCCR).

Es difícil comprender las razones por las cuales los autores de la reforma rumana prefirieron abandonar una norma especial para regular el depósito de títulos valores; éste reenvío puede ser causa de debate en cuanto a la aplicación de normas generales en la hipótesis de nuestro estudio.

Para estimar la responsabilidad del instituto de crédito, en ausencia de una estipulación expresa, será necesario destacar cada vez las obligaciones contractuales, obra difícil incluso en el espacio teórico ${ }^{\mathrm{T} 2}$.

El párrafo 2 del artículo 2I92 NCCR es una reproducción del art. I838 párrafo 3 del Código Civil italiano: Al instituto de crédito corresponde una compensación en la medida establecida por el contrato, o por los usos, así como el reembolso de los gastos necesarios realizados por él.

\footnotetext{
${ }^{\text {II }}$ Véase el párrafo I del artículo I838 del Código Civil italiano.

${ }^{\mathrm{I} 2}$ GARRIGUES, J., Contratos bancarios, cit., págs. 4I6-424.
} 
Mientras que con el fin de evitar la posible limitación en cuanto a la responsabilidad del banco, el párrafo 3 del artículo 2I92 NCCR establece que es nulo el pacto mediante el cual se exonere al instituto de crédito de observar, en la administración de los títulos, la prudencia y diligencia ordinaria.

\section{La apertura de crédito}

Además del depósito, el Código Civil define en su artículo 2193 la apertura de crédito como aquel contrato por el cual una entidad de crédito, una institución financiera no bancaria o cualquier otra entidad autorizada a través de ley especial llamada acreditante, se obliga a tener a disposición del cliente una suma de dinero por un cierto periodo de tiempo o por tiempo indeterminado.

El texto del art. 2 I93 es muy semejante al art. I842 del Código Civil italiano. Sin embargo, en comparación con su fuente de inspiración, los autores de nuestro Código sustituyeron la noción de «banco» por el concepto utilizado en la Directiva 2006/48/CE para definir la entidad financiera que tiene la calidad crediticia.

Desafortunadamente, los mismos autores, con demasiada efervescencia innovadora, utilizaron en lugar de «apertura de crédito» una terminología extraña, es decir, la «facilidad de crédito», proveniente del sistema jurídico anglosajón.

Salvo estipulación en contrario, a través de la apertura de crédito el cliente puede disponer de la suma acreditada en cantidades parciales, conforme a los usos, y reembolsar las sumas recibidas para mantener el fondo disponible.

Ante la falta de cumplimiento del acreditado por «motivos graves», según el art. 2I95 par. I NCCR, la entidad de crédito puede denunciar el contrato antes de la llegada del término. Como se puede fácilmente observar, el texto fue inspirado por el art. I845, par. I del Código Civil italiano, pero los autores rumanos utilizaron la noción de «motivos graves» en lugar de «giusta causa».

Como efecto jurídico principal, la revocación unilateral del crédito por el banco determina enseguida la extinción de derecho de disponer. Si la entidad de crédito hubiera denunciado de manera correcta el contrato, el deudor deberá devolver los fondos de los que hubiere dispuesto.

En ausencia de regulación específica no hay un plazo para la obligación de restituir dichos fondos ${ }^{\mathrm{I}}$. En esta hipótesis, el art. 2I95 par. 2 NCCR impone a la entidad que otorgue al cliente un mínimo de 55 días para la restitución de dichos fondos y varios accesorios.

Finalmente, de manera similar al Código Civil italiano, en el caso en que la apertura de crédito hubiera sido celebrada por tiempo indefinido, salvo usos o estipulación en contrario, cualquiera de las partes puede denunciar el contrato, con un preaviso de I5 días (art. 2195 par. 3 NCCR).

\footnotetext{
${ }^{13}$ Sobre esta «causa justa», véase GUTIÉRREZ GILSANZ, J., «El contrato de apertura de crédito», en SEQUEIRA, A., GADEA, E. y SACRISTÁN, F. (dirs), La contratación bancaria, cit., págs. 656 y ss.; y MOLLE, G., I contratti bancari, Giuffrè, Milano, I966, págs. 206 y ss.

${ }^{14}$ Véase GUTIÉRREZ GILSANZ, J., «El contrato de apertura de crédito», cit. pág. 657.
} 


\section{El contrato de cajas de seguridad}

La naturaleza jurídica del servicio de cajas de seguridad fue origen de largos debates en doctrina ${ }^{15}$, dado que esta determinación tiene una gran importancia práctica en cuanto a la acción de restitución a favor del cliente, la extensión de las obligaciones o, entre otros, los derechos de los terceros acreedores del banco o del cliente ${ }^{\mathrm{i} 6}$.

Dada la finalidad de la conservación y guarda de los objetos, algunos autores, especialmente en la doctrina francesa, consideraron el servicio de cajas de seguridad similar al depósito ${ }^{\mathrm{I}}$. En sentido contrario, otros autores acentuaron las similitudes con el arrendamiento de $\operatorname{cosas}^{\mathrm{r} 8}$.

Por contener elementos propios del depósito y del arrendamiento de cosas, tanto la doctrina mayoritaria como la jurisprudencia lo consideran un contrato con causa mixta, atípico, consensual, de ejecución continuada, oneroso y de adhesión ${ }^{\text {t9 }}$.

Aunque prestado por un gran número de bancos, este servicio no tiene ninguna normativa propia en los principales sistemas jurídicos europeos, con la excepción del sistema italiano. Pero tampoco el Código civil italiano, que regula en varios preceptos el servicio de cajas de seguridad, arts. I839 y ss., define este contrato bancario.

A su vez, el artículo 2196 del NCCR utiliza la noción del «contrato de arrendamiento» de cajas de seguridad, pero dicha norma no identifica la obligación esencial asumida por el instituto de crédito.

El texto, de manera semejante al Código civil italiano, acentúa el contenido de la obligación del banco, que responde frente al cliente de la idoneidad y la custodia de los locales y de la integridad de las cajas.

Por un lado, el banco debe tomar todas las medidas necesarias para evitar que cualquier otra persona abra la caja. Por otro lado, el banco es responsable de la integridad de la caja, lo que no supone dos obligaciones distintas, sino una prestación única ${ }^{20}$. Otra obligación del banco se refiere a permitir el acceso a la caja de seguridad.

El Código no tiene ninguna disposición en cuanto a obligaciones negativas del inquilino, si bien, según los usos bancarios, este no puede introducir en la caja de seguridad objetos degradables o peligrosos.

${ }^{15}$ Véase MOLLE, G. I contratti bancari, cit., pág. 607.

${ }^{16}$ GARRIGUES, J. Contratos bancarios, cit., pág. 455.

${ }^{17}$ Vid. RIPERT, G., Traite elementaire de droit commercial, Paris, Librairie Generale de Droit et Jurispruence, I95I, pág. 855 .

${ }^{18}$ Vid. GARRIGUES, J., Contratos bancarios, cit., pág. 45; FERRI, G., Manuale di diritto commerciale, Torino, Utet Giuridica, 20I0, pág. 94I; y GALGANO, F., Diritto civile e commerciale, II, 2, Padova, Cedam, 20Io, pág. 203.

${ }^{19}$ Vid. CORTES, L. J., «Contratos bancarios II», en URÍA, R., y MENÉNDEZ, A. (dirs.), Curso de derecho mercantil, t. II, Madrid, Civitas, 200I, págs. 555 y ss.; y MARTÍNEZ ROSADO, J., «El servicio de alquiler de cajas de seguridad», en SEQUEIRA, A., GADEA, E. y SACRISTÁN, F. (dirs), La contratación bancaria, cit. pág. I4I3.

${ }^{20}$ MOLLE, G., I contratti bancari, cit., págs. 623 y 624 . 
Cuando varias personas han alquilado la misma caja de seguridad, el artículo 2197 parágrafo I NCCR permite, en ausencia de una estipulación contractual contraria, el acceso a la caja a cada uno de ellos.

Cuando hay más titulares de la caja y uno de ellos fallece, el instituto de crédito no puede abrir la caja sin el consentimiento de todas las personas autorizadas o, en su defecto, en las condiciones establecidas por el juez (art. 2I97 par. I NCCR).

La misma norma se aplica en el caso del fallecimiento del único usuario y también en el proceso de la reorganización (en la hipótesis de la insolvencia empresarial) o de la disolución de la persona jurídica.

Por su parte, el artículo 2I98 NCCR fija las condiciones para poder abrir la caja de seguridad en ausencia del titular.

Transcurrido el tiempo estipulado en el contrato y notificando al cliente por carta certificada con acuse de recibo, después de tres meses de dicha notificación, el banco puede solicitar al tribunal la autorización judicial extraordinaria para abrir la caja. La caja de seguridad se abre ante un notario público y, en su caso, sin perjuicio de las medidas cautelares establecidas por el tribunal.

El tribunal podrá también adoptar las medidas necesarias para conservar los objetos descubiertos y para venderlos con el propósito de cubrir el alquiler, los gastos incurridos por el banco y, eventualmente, los daños.

\section{Conclusiones}

En primer lugar, el reconocimiento de la autonomía de los contratos bancarios era absolutamente necesario, sobre todo porque a través del uso de estos instrumentos jurídicos las operaciones de intermediación financiera se han convertido en la actividad exclusiva de los sujetos identificados y supervisados por la ley bancaria.

Por otra parte, cabe señalar que a diferencia del Código Civil italiano, que tiene reglas específicas para el descuento bancario, operación esencial en la historia del derecho mercantil, el nuevo Código Civil rumano no reconoce dicha institución en el ámbito de la contratación bancaria.

El art. I858 del Código Civil italiano define el descuento como un contrato por el cual el banco, previa deducción de un interés, anticipa al cliente el importe de un crédito contra terceros todavía no vencido, mediante la cesión, salvo buen fin, de dicho crédito.

La cesión de crédito por parte del cliente descontado no es liberatoria de su obligación de pagar porque se trata de una cesión pro solvendo ${ }^{21}$.

En otras palabras, incumbe al cliente una obligación de restitución que está suspensivamente condicionada al impago por parte del deudor cedido ${ }^{22}$.

\footnotetext{
${ }^{21}$ GARRIGUES, J., Contratos bancarios, cit., pág. 29I.

${ }^{22}$ Casación italiana de 15 de mayo de I990, n. 4I63, Giurisprudenza commerciale, I, I990, pág. 257I.
} 
En ausencia de normas especiales, el contrato de descuento será regulado por las disposiciones contenidas en el capítulo I, La cesión de crédito (arts. I566 a I592 NCCR), del título VI, Transmisión y transformación de las obligaciones.

El descuento sería una forma especial de la cesión de crédito y en virtud del art. 1585 par.I NCCR por ser contrato oneroso incumbe al cedente ofrecer garantía, pero se trata de una cesión pro soluto; para perfeccionar una cesión pro solvendo es necesario que haya una estipulación expresa según el art. 1585 par. 2 NCCR.

Es difícil comprender las razones por las cuales los autores de la reforma rumana no reconocieron la autonomía y fisionomía propia del descuento dado que, incluso en otros sistemas romanistas -como el español-, el contrato es considerado por la doctrina mayoritaria una figura distinta entre los contratos bancarios ${ }^{23}$.

${ }^{23}$ BETANCOR SÁNCHEZ, V. E. y ESTUPIÑÁN CÁCERES, R., «De la esclavitud documental a la ausencia de documento en el descuento bancario», en Revista de derecho bancario y bursátil, IOI, 2006, pág.I63. 